\title{
Propagação vegetativa de Aloysia triphylla (L'Hér.) Britton em função da concentração de AIB e do comprimento das estacas
}

\author{
PAULUS, D. ${ }^{1 *}$; VALMORBIDA, R.; TOFFOLI, E; PAULUS, E². \\ 'Universidade Tecnológica Federal do Paraná - Campus Dois Vizinhos, Estrada para Boa Esperança, Km 04, \\ Caixa Postal, 157, CEP: 85660 000, Dois Vizinhos, Paraná. *dalvapaulus@utfpr.edu.br; ²Universidade Federal \\ de Santa Maria - Departamento de Solos, Avenida Roraima, 1000, Cidade Universitária, Bairro Camobi, CEP: \\ 97105-900, Santa Maria-Brasil. *dalvapaulus@utfpr.edu.br
}

RESUMO: A Aloysia triphylla (L'Hér.) Britton é uma planta medicinal de porte arbustivo com folhas aromáticas que possuem óleo essencial rico em citral. A crescente demanda da indústria farmacêutica e cosmética pelo óleo essencial de A. triphylla promoveram grande interesse sobre o cultivo dessa espécie. A estaquia é um dos principais métodos de propagação devido à dificuldade em obter sementes, e também pela vantagem dos descendentes serem iguais à planta-matriz. O objetivo do trabalho foi avaliar o efeito de diferentes concentrações de AIB e do comprimento das estacas no enraizamento de estacas de $A$. triphylla. O experimento foi conduzido em ambiente protegido no período de Novembro de 2010 a Janeiro de 2011. O delineamento experimental foi inteiramente casualizado em esquema fatorial onde os fatores foram cinco concentrações de ácido indol butírico (AIB) $\left(\mathrm{mg} \mathrm{L}^{-1}\right): 0,250,500,1000$ e 1500, e quatro comprimentos de estaca: 4, 6, 8 e $10 \mathrm{~cm}$. As estacas tiveram a base imersa em solução de AIB e foram colocadas para enraizar em substrato comercial Mecplant $\circledast$. As variáveis analisadas foram: comprimento do sistema radicular, percentagem de estacas enraizadas (\%), número de brotações, massa fresca e seca da parte aérea, e massa seca das raízes. Nas condições em que o estudo foi realizado os resultados mostraram que o comprimento das estacas e concentração de AIB afetam o desenvolvimento das estacas, apresentando ajuste quadrático e linear para as variáveis analisadas. As mudas obtidas a partir de estacas com 10 $\mathrm{cm}$ e concentração de $1500 \mathrm{mg} \mathrm{L}^{-1}$ de AIB apresentaram a maior percentagem de enraizamento e as maiores médias para o comprimento do sistema radicular, número de brotações, massa fresca e seca da parte aérea.

Palavras-chave: Cidró; estaquia; regulador de crescimento

ABSTRACT: Vegetative propagation of Aloysia triphylla (L'Hér.) Britton according to IBA and length of cuttings. Aloysia triphylla (L'Hér.) Britton is a medicinal plant shrub with aromatic leaves, which have essential oil rich in citral. The increasing demand of the pharmaceutical and cosmetic industries for the $A$. triphyllaessential oil provided a greater interest in the cultivation of this species. Cutting is one of the main methods of propagation, due to the difficulty in obtaining seeds and also for the benefit of descendants being equal to the parent plant. The objective of this study was to evaluate the effect of different concentrations of IBA and length of cuttings in the rooting of $A$. triphylla. The experiment was carried out in a protected environment in the period from November 2010 to January 2011. The experimental design was completely randomized using the factorial design where the factors were five concentrations of indole butyric acid (IBA) (mg L-1): 0, 250, 500, 1000 and 1500, and four lengthsforthe cuttings: 4, 6, 8 and $10 \mathrm{~cm}$. The cutting base was immersed in a solution of IBA and placed into the rooting Mecplant ${ }^{\circledR}$ commercial substrate. The variables analyzed were: root length, percentage of rooted cuttings (\%), number of shoots, fresh and dry weight of the shoots, and dry weight of the roots. Under the conditions in which the study was conducted, the results showed that the length of the cuttings and IBA concentration affect the development of the cuttings, with linear and quadratic adjustment for the variables analyzed. The seedlings of cuttings with $10 \mathrm{~cm}$ and the concentration of $1500 \mathrm{mg} \mathrm{L}^{-1}$ IBA showed the highest percentage of rooting and the highest averages for length of the root system, number of shoots, fresh and dry weight of the shoots.

Keywords: Cidró; cutting; growth regulator

Recebido para publicação em 16/09/2011

Rev. Bras. PI. Med., Campinas, v.16, n.1, p.25-31, 2014. 


\section{INTRODUÇÃO}

A Aloysia triphylla (L'Hér.) Britton (Verbenaceae) é um arbusto de 2 a 3 metros, muito ramificado e ereto conhecido popularmente como Cidró. É uma erva originária do Chile que possui propriedade adstringente e aromática, rica em óleo volátil, agindo como sedativo brando, também ajuda na digestão e contra resfriados. $\mathrm{Na}$ aromaterapia é usada contra problemas nervosos e digestivos, e para acnes. Na culinária é servida como recheio de bolos, no preparo de licores, sucos, pães, e para dar aroma às carnes. Suas folhas retêm muito bem seu aroma de citral, mesmo depois da secagem, tornando-se um componente indispensável nos "potpourris" muito empregados para aromatizar ambientes. Além de tudo, esta espécie possui propriedade inseticida e bactericida (Lorenzi \& Matos, 2008).

Segundo El-Hawary et al., (2012) as folhas de $A$. triphylla preparadas na forma de chás apresentam atividade antipirética, antiinflamatória e analgésica, e propriedades sedativas, digestivas e antioxidantes. Os compostos fenólicos (principalmente flavonóides, ácidos fenólicos e fenilpropanóides) foram relatados por Quirantes Piné et al., (2009) por serem responsáveis pela maior parte das atividades farmacológicas da A.triphylla, tais como, analgésicas, antiinflamatórias e antioxidantes.

A comercialização do óleo essencial de Aloysia triphylla e a grande demanda da indústria farmacêutica e cosmética, principalmente pelo citral, utilizado na fabricação de perfume, síntese de ionona (perfume da violeta), beta-caroteno e vitamina A, proporcionaram maior interesse no cultivo dessa espécie (Czepack \& Cruciol, 2003).

A Aloysia triphylla é dificilmente propagada via semeadura, devido às sementes serem pequenas, de difícil coleta, e ocorrência de dormência e/ ou de imaturidade, com baixos índices de germinação (Pimenta et al., 2007). Segundo Juliani et al., (1999) a propagação da $A$. triphylla é feita principalmente por estacas, na primavera e verão, onde verifica-se a presença de folhas jovens e brotações novas nas hastes da planta. No outono, a planta perde as folhas e as hastes ficam desidratadas (secas) com aspecto de planta morta, até o final do inverno.

A propagação vegetativa tem inúmeras vantagens em relação à propagação sexuada, por ser uma técnica simples, rápida e barata, permitido produzir muitas mudas em espaço reduzido com maior uniformidade do estande, e manter as características genéticas da planta doadora (Hartmann \& Kester, 1990). A estaquia é um método de propagação no qual ocorre a indução do enraizamento adventício em segmentos destacados da planta-mãe que, uma vez submetidos a condições favoráveis, originam uma muda (Fachinello et al., 2005).
Com relação a essa técnica é importante ressaltar que fatores externos de natureza física ou química, como intensidade de luz, temperatura, umidade, quantidade de água, podem influenciar na formação de raízes adventícias, estimulando ou inibindo o enraizamento, além de substâncias produzidas pelas plantas, como auxinas e citocianinas, responsáveis pelo início do processo da formação de raízes (Assis \& Teixeira, 1998).

A utilização de reguladores vegetais tem por finalidade induzir o processo de formação de raízes, aumentar a porcentagem de estacas enraizadas, o número e a qualidade das raízes formadas, e a uniformidade do enraizamento (Miranda et al., 2004).

As auxinas são reguladores vegetais indicados para indução de enraizamento, sendo o ácido indolbutírico (AIB) um dos mais utilizados por ser um composto indólico sintético que apresenta algumas características favoráveis à sua utilização em grande escala na propagação vegetativa de plantas, como, por exemplo: ser fotoestável, atóxico, e não ser atacado por ação biológica (Pasqual et al., 2001).

As espécies pertencentes à família Verbenaceae diferem muito quanto à resposta de enraizamento com reguladores de crescimento. Lolli (2001) constatou que a concentração de 2000 $\mathrm{mg} \mathrm{L}^{-1}$ foi a melhor para o enraizamento de estacas semilenhosas com folhas de Lippia alba (Mill.). Stefanni et al.,(2004) informam que a concentração de $250 \mathrm{mg} \mathrm{L}^{-1}+$ ácido bórico apresentou os melhores resultados para o enraizamento de estacas de $A$. triphylla.

Estudos sobre a propagação de espécies medicinais são de elevada importância, uma vez que servem de base para a domesticação e o sucesso do cultivo dessas plantas (Carvalho Junior et al., 2009). No entanto, ainda há escassez desses estudos, como no caso da $A$. triphylla, especialmente quando ainda não há informações científicas quanto ao tamanho de estaca a ser utilizada.

O presente trabalho foi realizado com o objetivo de avaliar o efeito de diferentes concentrações de AIB e comprimento de estacas no enraizamento de estacas caulinares de Aloysia triphylla.

\section{MATERIAL E MÉTODO}

O experimento foi conduzido em casa de vegetação modelo arco simples, protegida no teto por filme transparente de polietileno de baixa densidade, no período de novembro de 2010 a janeiro de 2011, na área experimental da Universidade Tecnológica Federal do Paraná (UTFPR) Campus Dois Vizinhos, Paraná.

Rev. Bras. PI. Med., Campinas, v.16, n.1, p.25-31, 2014. 
O delineamento experimental utilizado foi inteiramente casualizado em esquema fatorial onde os fatores foram cinco concentrações de ácido indol butírico (AIB) (mg L-1): 0, 250, 500, 1000 e 1500 e comprimento de estacas: 4, 6, 8 e $10 \mathrm{~cm}$. Foram utilizadas 20 estacas por repetição, totalizando 360 estacas.

As estacas apicais com 4, 6, 8 e $10 \mathrm{~cm}$ de comprimento foram podadas de modo a possuírem no mínimo dois nós, obtidas de plantas matrizes localizadas no horto medicinal da UTFPR. As folhas presentes nos ramos, em pequeno número, foram retiradas, visando à uniformização das estacas.

As estacas tiveram a base imersa em solução hidroalcoólica de AIB com as concentrações de (mg L-1): zero, 250, 500, 1000 e 1500 que foram obtidas por meio da dissolução de ácido indol3-butírico $\left(\mathrm{C}_{12} \mathrm{H}_{13} \mathrm{NO}_{2}\right)$ p.a., com $99 \%$ de pureza, produzido pela MERCK ${ }^{\circledR}$ em solvente composto de $50 \%$ de água destilada e $50 \%$ de álcool etílico p.a. de $99,5 \%$ de pureza (Hartmann \& Kester, 1990), durante cinco minutos e após colocadas para enraizar em tubetes com dimensões de diâmetro de bocal de $38 \mathrm{~mm}, 8$ estrias, altura de $120 \mathrm{~mm}$ e volume de $80 \mathrm{~cm}^{3}$, contendo substrato comercial Mecplant $\circledast$. Os tubetes foram organizados em grade de arame suporte, de forma suspensa, mantidos em ambiente protegido. As irrigações foram realizadas com um regador, três vezes ao dia.

As determinações do comprimento do sistema radicular, percentagem de estacas enraizadas (\%), número de brotações, massa fresca da parte aérea e raízes foram realizadas aos 53 dias após o transplantio (DAT). As raízes e parte aérea foram colocadas em estufa com circulação de ar forçada a $65^{\circ} \mathrm{C}$ até peso constante, para obtenção da massa seca.

Os dados foram submetidos à análise da variância e regressão polinomial, utilizando-se o programa estatístico SAS (SAS, 1999).

\section{RESULTADO E DISCUSSÃO}

Não houve interação significativa entre comprimento de estacas e doses de AIB. Observouse efeito significativo do tamanho de estaca para as variáveis massa da matéria fresca e seca da parte aérea, apresentando regressão quadrática (Figura 1). Os melhores resultados de massa da matéria fresca e seca da parte aérea foram obtidos com o comprimento de estaca de $10 \mathrm{~cm}$.

A massa da matéria seca do sistema radicular das plantas que corresponde à emissão de raízes adventícias apresentou diferença significativa, com regressão quadrática, de forma similar à variável comprimento do sistema radicular (Figura 1). Os melhores resultados de comprimento
$(16 \mathrm{~cm})$ e massa seca do sistema radicular $(0,19 \mathrm{~g}$ planta $^{-1}$ ) foram obtidos com estacas de $10 \mathrm{~cm}$ de comprimento. As estacas de menor comprimento resultaram em menor massa da matéria seca e comprimento do sistema radicular. Esse fato pode ser explicado pelo baixo nível de reservas energéticas presentes nessas estacas (Nicoloso et al., 2001).

Segundo Lima et al., (2006) a massa da matéria seca das raízes é um parâmetro importante na avaliação do vigor da estaca, onde estacas com poucas reservas têm baixo vigor, o que pode ser verificado nas estacas menores.

Nas condições em que o presente estudo foi realizado o sistema radicular das estacas maiores apresentou-se ramificado, indicando vigor do material propagativo formado. Isso pode ser explicado pelo comprimento das estacas, que é um fator de grande importância no desenvolvimento do sistema radicular, uma vez que, estacas maiores apresentam quantidade maior de reservas nutritivas, as quais podem ser translocadas para a base da estaca e auxiliar na formação das raízes (Hartmann et al., 2004). A maior ramificação das raízes implica em aumento da área de solo a ser explorada, aumentando-se a taxa de absorção de água e nutrientes, o que certamente proporcionará melhor desenvolvimento da estaca quando levada a campo (Carvalho Júnior et al., 2009).

O número de brotos apresentou diferença significativa, constatando-se efeito quadrático. O maior número de brotos (7) foi obtido com estacas de $10 \mathrm{~cm}$ de comprimento. Estacas de comprimento maior apresentam maior quantidade de reservas, sendo que a formação de novas estruturas na parte aérea da estaca funciona como um forte dreno consumidor das reservas de carboidratos e compostos nitrogenados (Hartamnn et al., 2004).

Observou-se expressiva influência do tamanho das estacas na fitomassa fresca e seca da parte aérea e das raízes, sendo que as estacas de $10 \mathrm{~cm}$ apresentaram os melhores resultados, o que pode estar relacionado com a maior emissão de brotações nesse tamanho de estaca.

A influência do comprimento da estaca de ramo no enraizamento de ginseng (Pfaffia glomerata) (Spreng.) Pedersen também foi verificada por Nicoloso et al., (2001), que constaram em estacas $(10,15$ e $20 \mathrm{~cm})$ de que as mudas obtidas de estacas de $10 \mathrm{~cm}$ apresentaram maior número de brotações, comprimento das brotações, massa seca de talos e massa da matéria seca total por estaca, que aquelas de $20 \mathrm{~cm}$ de comprimento.

A percentagem de estacas enraizadas foi influenciada pelo comprimento de estaca, constatando-se efeito quadrático (Figura 1). Estacas com $10 \mathrm{~cm}$ de comprimento apresentaram maior

Rev. Bras. PI. Med., Campinas, v.16, n.1, p.25-31, 2014. 
percentagem de enraizamento (90\%), enquanto que estacas com $4 \mathrm{~cm}$ de comprimento apresentaram a menor percentagem (65\%) de enraizamento quando comparada aos demais comprimentos, o que pode ser explicado pelo baixo nível de reservas nutritivas presentes nessas estacas (Nicoloso et al., (2001).

Resultados semelhantes foram verificados por Carvalho Júnior et al., (2009) com estacas de alecrim-pimenta (Lippia sidoides Cham.). Os autores constataram que estacas maiores que $14 \mathrm{~cm}$ apresentaram os melhores resultados de fitomassa seca das brotações $(1,10 \mathrm{~g})$ e das raízes $(0,59 \mathrm{~g})$ e porcentagem de enraizamento $(98 \%)$. Os autores atribuem esse fato à maior emissão de brotações nesse comprimento de estaca, indicando maior vigor do material propagativo.

Biasi \& Costa (2003), avaliando a propagação vegetativa de $L$. alba por meio de estacas de diferentes comprimentos $(5,10,15 \mathrm{e}$ $20 \mathrm{~cm}$ ) observaram que o aumento do tamanho da estaca proporcionou aumento linear nas variáveis percentagem de enraizamento e número de raízes emitidas por estaca, sendo que, todas as estacas de $20 \mathrm{~cm}$ enraizaram, o que foi atribuído pelos autores, à maior quantidade de reservas de carboidratos presentes nas estacas maiores, que seriam utilizadas para a formação de brotos e de raízes novas (Hartmann et al., 2004).

Os resultados da massa da matéria fresca e seca da parte aérea apresentaram diferenças significativas em função das concentrações de AIB avaliadas, apresentando regressão quadrática e linear, respectivamente (Figura 2). A concentração de $1500 \mathrm{mg} \mathrm{L}^{-1}$ de AIB resultou em maior massa da matéria fresca e seca $\left(0,84\right.$ e $\left.0,35 \mathrm{~g}^{\text {planta-1 }}{ }^{-1}\right)$, respectivamente. As estacas enraizadas na concentração zero de AIB apresentaram os menores valores de massa da matéria fresca e seca. Para massa da matéria seca da raíz não ocorreu efeito significativo em função das concentrações avaliadas, sendo o valor médio de $0,13 \mathrm{~g}_{\text {planta-1 }}{ }^{-1}$.

Para o comprimento do sistema radicular verificou-se diferença significativa, sendo a equação de regressão quadrática (Figura 2). O maior comprimento do sistema radicular $(20 \mathrm{~cm})$ foi obtido com a dosagem de $1500 \mathrm{mg} \mathrm{L}^{-1}$ de AIB.

O tratamento das estacas com auxinas propiciou efeitos benéficos à massa da matéria fresca e seca da parte aérea e a qualidade do sistema radicular das estacas. Resultados semelhantes do efeito benéfico do AIB para o enraizamento de estacas de $A$. triphylla, também foram verificados por Stefanini et al. (2004) ao avaliarem a influência de reguladores de crescimento e ácido bórico no enraizamento de estacas dessa espécie, constando que os melhores resultados de número de raízes, comprimento das raízes, porcentagem de enraizamento, massa fresca e secas das folhas foram observados na concentração de $250 \mathrm{mg} \mathrm{L}^{-1}$ de AIB + ácido bórico em relação as concentrações de $150 \mathrm{mg} \mathrm{L}-1$ de AIB, $150 \mathrm{mg} \mathrm{L}-1$ de AIB + ácido bórico, $250 \mathrm{mg} \mathrm{L}-1$ de AIB.

Oliveira et al., (2011) constataram efeito positivo de concentrações relativamente altas de AIB (4000 mg L-1) na sobrevivência e enraizamento de estacas de Hyptis leucocephala Mart. ex Benth. e Hyptis platanifolia Mart. ex Benth. Os autores afirmam que as auxinas são essenciais no processo de enraizamento, possivelmente por estimularem a síntese de etileno, o que favorece a emissão de raízes. Por outro lado, a excessiva concentração de auxina pode ser tóxica à planta, ocasionando formação de calos na base das estacas, afetando a rizogênese e o crescimento da parte aérea (Pasqual et al., 2001). Nesse trabalho não foram verificados efeitos fitotóxicos e formação de calos na base das estacas com as concentrações avaliadas.

A capacidade de uma estaca emitir raízes é função de fatores endógenos e das condições ambientais proporcionadas ao enraizamento (Fachinello et al., 2005). Segundo os autores, cada espécie possui seu valor máximo de aplicação exógena de regulador vegetal e este comportamento pode estar relacionado com o fato das estacas possuírem certa quantidade endógena de hormônios, promotores ou inibidores de enraizamento.

O teor adequado de auxina exógena, para estímulo do enraizamento, depende da espécie e da concentração de auxina existente no tecido, sendo que o fornecimento exógeno de auxina, em certas quantidades, pode promover alteração hormonal, favorecendo ou não o enraizamento, no caso da $A$. triphylla verificou-se que o AIB na concentração de $1500 \mathrm{mg} \mathrm{L}^{-1}$ favoreceu o enraizamento.

Por outro lado, Oliveira et al., (2008) avaliaram o efeito de diferentes concentrações de AIB (0, 250, 500, 750 e $1000 \mathrm{mg} \mathrm{L}^{-1}$ ) em Lippia sidoides Cham. e constataram que o número de brotações por estaca diminuiu à medida que a concentração de AIB aumentou e o número de raízes por estacas e a porcentagem de estacas enraizadas apresentaram maior enraizamento na concentração de $250 \mathrm{mg} \mathrm{L}^{-1}$; também informam que o desenvolvimento de raízes foi inibido pelo aumento na concentração de AIB. Segundo os autores, as respostas variadas ao uso de reguladores vegetais no enraizamento, possivelmente ocorre em consequência de diferenças ambientais, ou seja, local onde o experimento foi realizado, da intensidade luminosa, temperatura, umidade, além de variações hormonais de cada espécie estudada.

Verificou-se diferença significativa para a percentagem de estacas enraizadas e número de brotos, com regressão quadrática (Figura 2).

Rev. Bras. PI. Med., Campinas, v.16, n.1, p.25-31, 2014. 
A

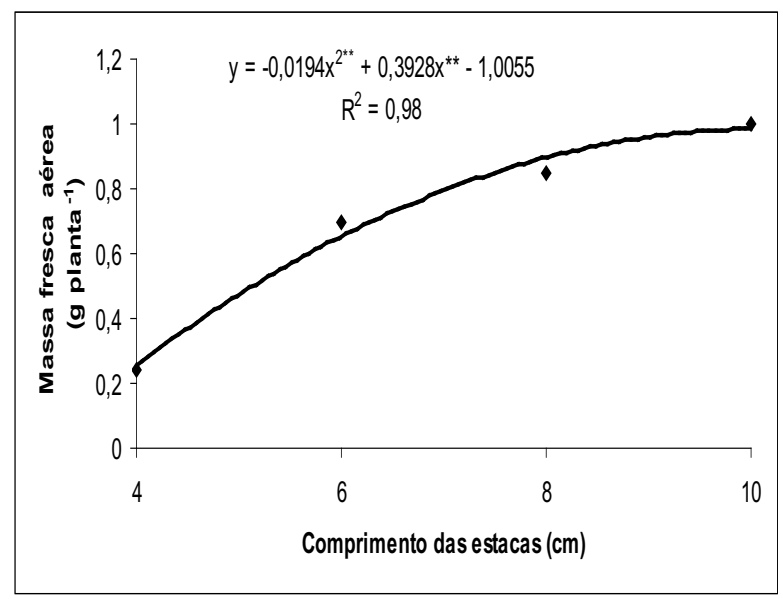

C
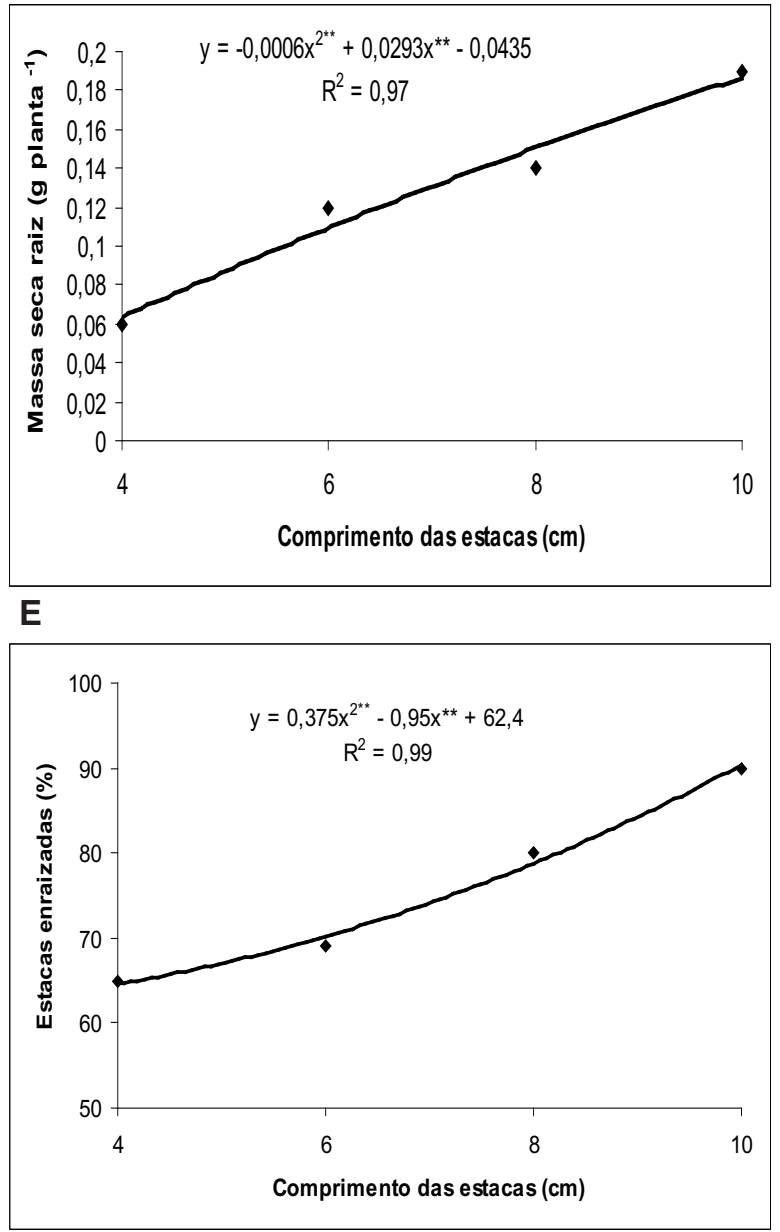

** significativo a $1 \%$ de probabilidade pelo teste $\mathrm{F}$;
B

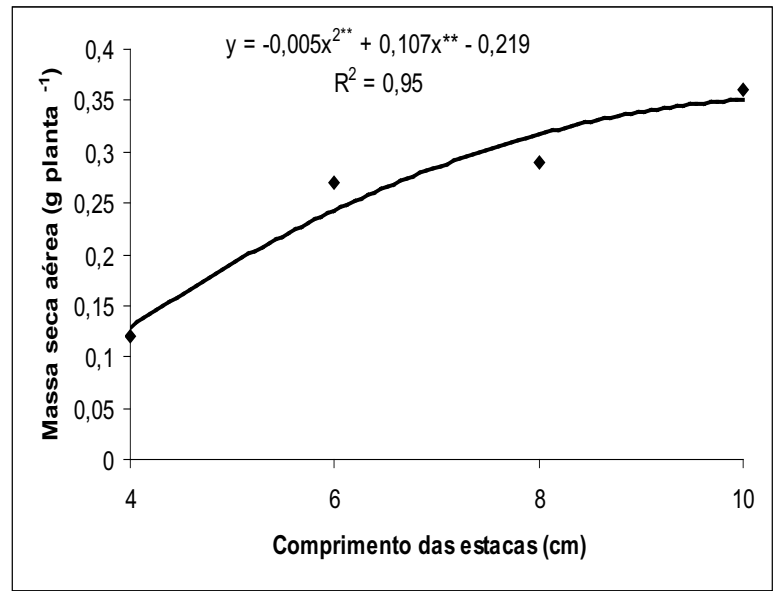

D

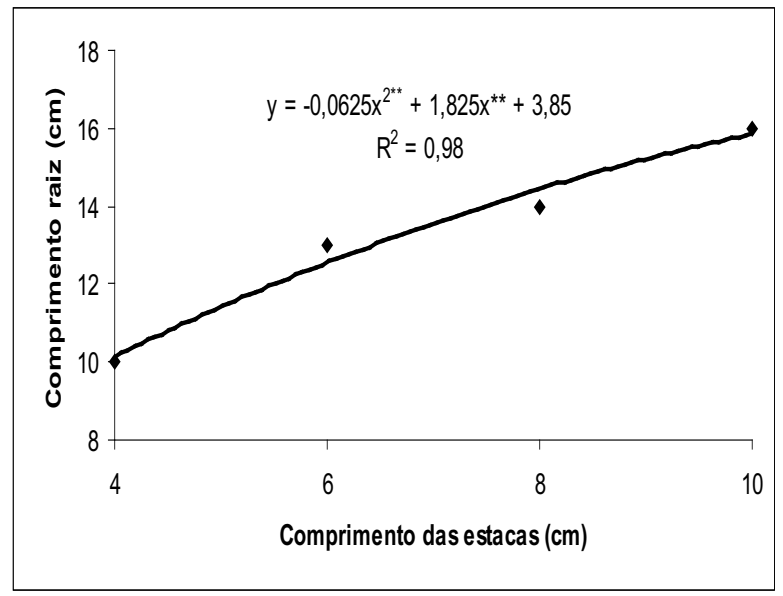

$\mathbf{F}$

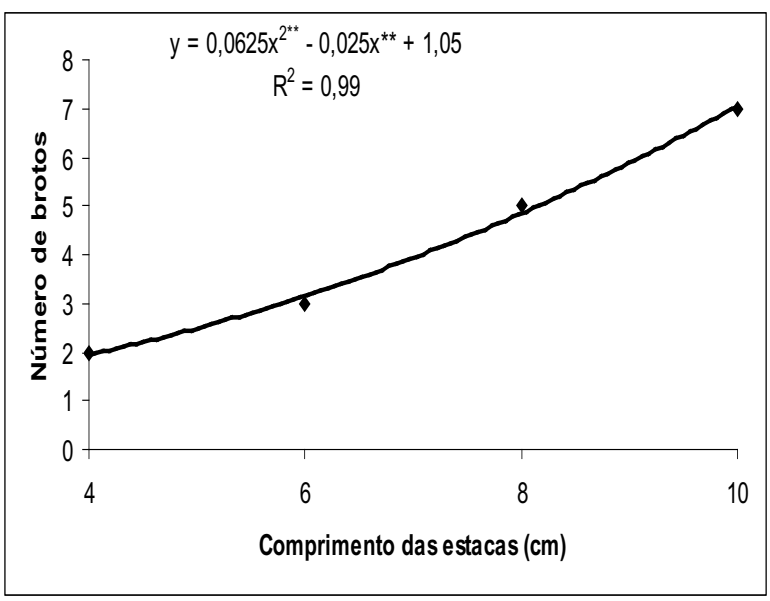

FIGURA 1. Massa fresca da parte aérea (a); massa seca da parte aérea (b); massa seca de raízes (c); comprimento das raízes (d); porcentagem de estacas enraizadas (e); número de brotos (f) de estacas de Aloysia triphylla em função de comprimentos das estacas. UTFPR, Dois Vizinhos, 2010.

Pode-se verificar que a maior percentagem de estacas enraizadas (95\%) e número de brotos (5) foi obtida com a concentração de $1500 \mathrm{mg} \mathrm{L}^{-1}$ de AIB. A menor percentagem de estacas enraizadas
(68\%) foi obtida sem o uso de AIB. O efeito benéfico dos reguladores de crescimento no enraizamento de estacas também foi constatado por Pimenta et al., (2007) que avaliaram a propagação por estaquia de

Rev. Bras. PI. Med., Campinas, v.16, n.1, p.25-31, 2014. 
A

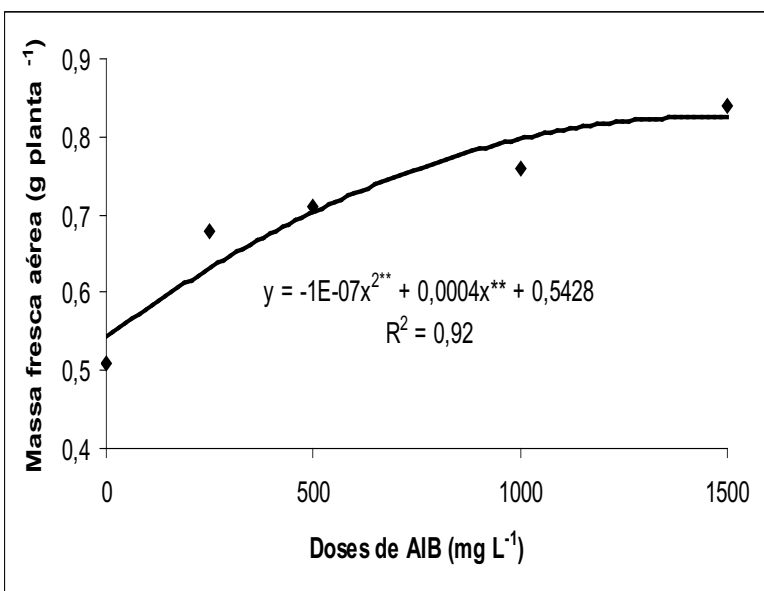

C

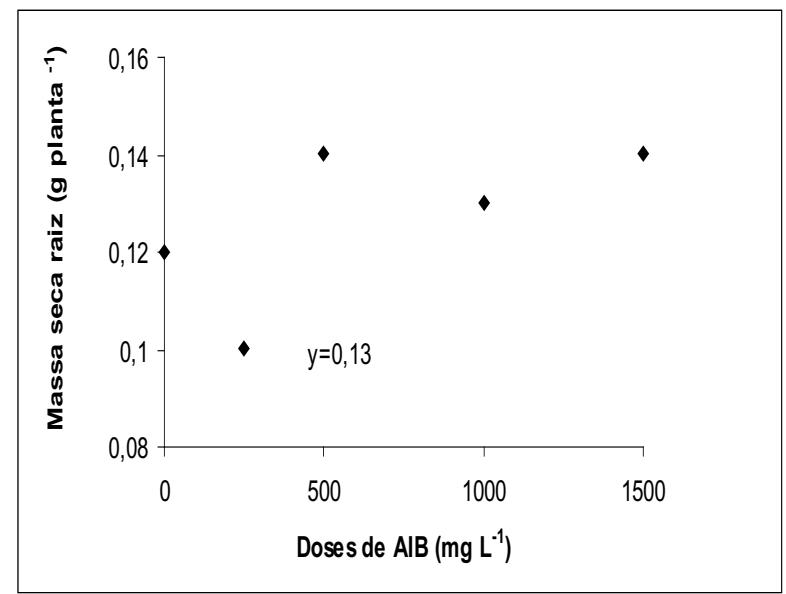

E

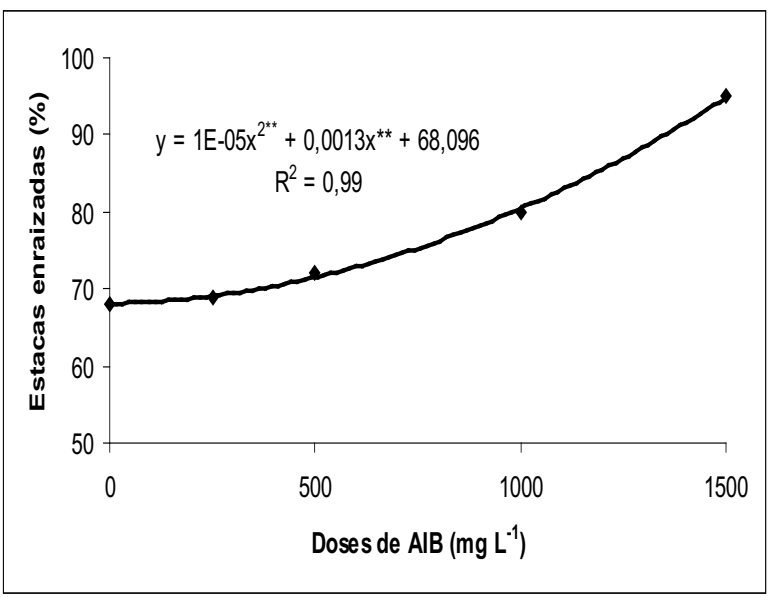

B

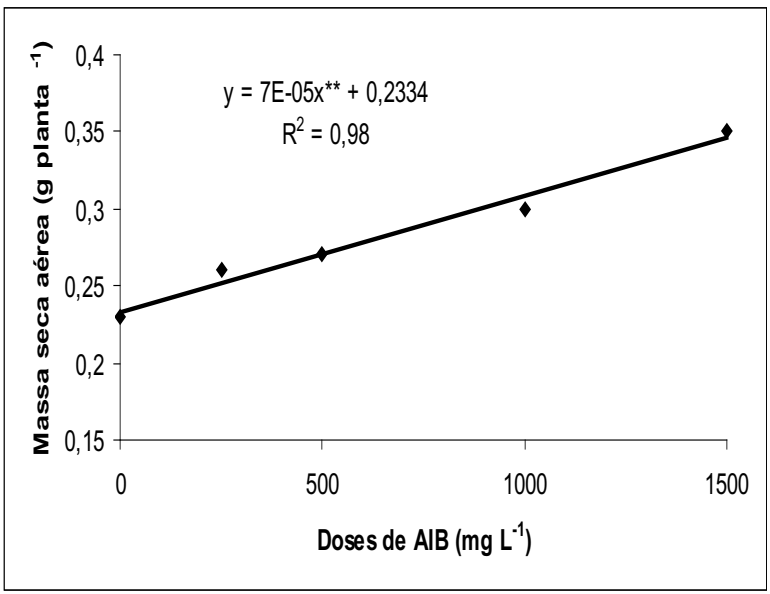

D

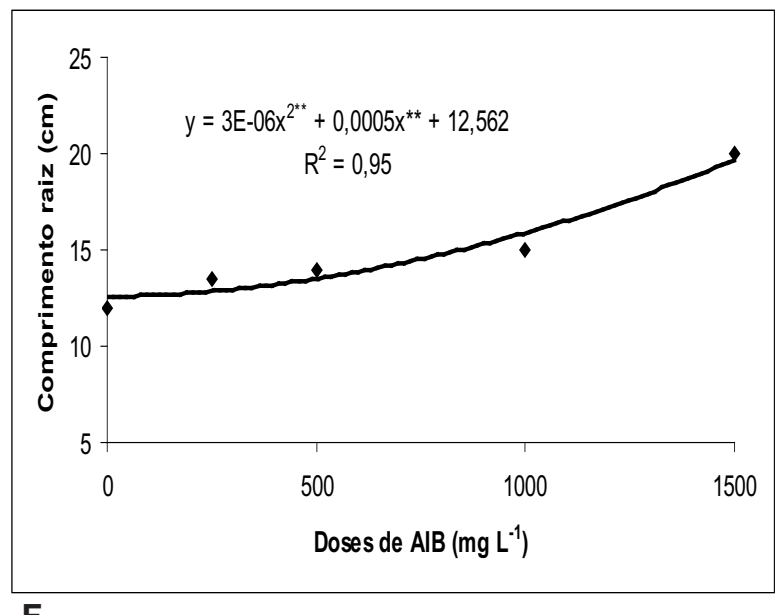

$\mathbf{F}$

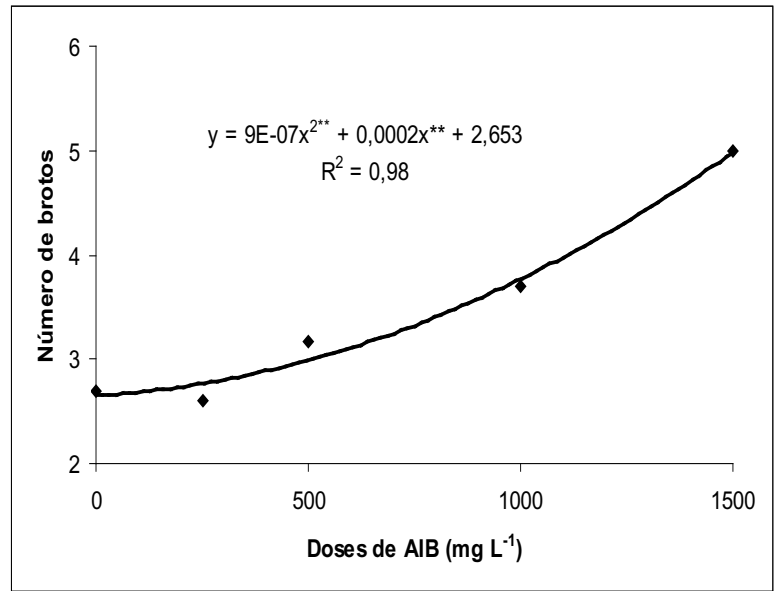

** significativo a $1 \%$ de probabilidade pelo teste $\mathrm{F}$;

FIGURA 2. Massa fresca da parte aérea (a); massa seca da parte aérea (b); massa seca de raízes (c); comprimento das raízes (d); porcentagem de estacas enraizadas (e); número de brotos (f) de estacas de Aloysia triphylla em função de concentrações de AIB. UTFPR, Dois Vizinhos, 2010.

quatro diferentes quimiotipos de Lippia alba (Mill.) com utilização de diferentes auxinas, constataram que o AIB foi a auxina mais eficiente na indução de rizogênese nas estacas, em contraste ao ácido indolacético (AIA) que estimulou o enraizamento dos quimiotipos em menor intensidade. Segundo Hartman et al., (2004) a maior eficiência de indução ao enraizamento do AIB pode ser atribuída a 
estrutura química, menos propensa à ação catalítica causada pela ação das enzimas de degradação, naturalmente presente nas estacas.

Nas condições em que o presente estudo foi realizado, pode-se afirmar que a $A$. triphila apresentou cofatores nas estacas e gemas, favoráveis a propagação vegetativa por estaquia, com baixa quantidade de substâncias inibidoras de enraizamento. Pode-se tornar o enraizamento mais eficiente, utilizando-se substâncias promotoras do enraizamento, como é o caso do ácido indolbultírico (AIB), possibilitando para o produtor de óleo essencial benefícios em termos de maior facilidade de produção de estacas.

\section{CONCLUSÃO}

Nas condições em que o presente estudo foi realizado conclui-se que o tamanho das estacas de Aloysia triphylla afeta o enraizamento e o desenvolvimento inicial de mudas e que estacas de $10 \mathrm{~cm}$ de comprimento e a concentração de $1500 \mathrm{mg}$ $\mathrm{L}^{-1}$ proporcionaram maior enraizamento de estacas.

\section{REFERÊNCIA}

ASSIS, T.F.; TEIXEIRA, S.L. Enraizamento de plantas lenhosas. Cultura de tecidos e transformação de plantas. Brasília: EMBRAPA - SPI, p.261-96, 1998.

BIASI, A.L; COSTA, G. Propagação vegetativa de Lippia alba. Ciência Rural, v. 33, p. 455-459, 2003.

CARVALHO JÚNIOR, W.G.O; MELO, M.T.P de; MARTINS, E.R. Comprimento da estaca no desenvolvimento de mudas de alecrim-pimenta. Ciência Rural, v.39, n.7, p.2199 -2202, 2009.

CZEPACK, M.P.; CRUCIOL, C.A.C. Produtividade e composição do óleo essencial de capim-limão (Cymbopogon citratus (DC) STAPF) em diferentes arranjos espaciais. In: SIMPÓSIO BRASILEIRO DE PLANTAS MEDICINAIS: DIAGNÓSTICO E PERSPECTIVAS, 2 ed. 2003, Campinas. Anais... Campinas: Instituto Agronômico, 2003. p.34-36.

EL HAWARY, S.S; YOUSIF, M.F.; MOTAAL, A.A.A.; ABD HAMEED, L.M; Bioactivities, phenolic compounds and in-vitro propagation of Lippia citriodora Kunth cultivated in Egypt. Bulletin of faculty of Pharmacy, Cairo University, p. 1110-1016, 2012, doi: :10.1016/j. bfopcu.2011.12.001. Disponível em: <http: //www. elsevier.com/locate/bfopcu>. Acesso em: 07 jun. 2012.

FACHINELLO, J.C.; HOFFMANN, A.; NACHTIGAL, J.C. Propagação de plantas frutíferas. Brasília: EMBRAPA, 2005. 221p.

HARTMANN, H.T; KESTER, D.E. Propagación de plantas: princípios y practicas. Ciudad del Mexico: Compania Editora Continental,1990. p.237-346. 760p.

HARTMANN, H.T; KESTER, D.E; DAVIES JR, R.T; GENEVE, RL. Plant propagation: principles and practices. 7 ed. New Jersey: Prentice Hall International,
2004. 880p.

JULIANI, H.R.; KOROCH, A.R.; JULIANI, H.R; TRIPI, V.S. Micropropagation of Lippia junelliana (Mold.) Tronc. Plant Cell, Tissue and Organ Culture, v. 59, n.8, p.175-179, 1999.

LIMA, R.L.S; SIQUEIRA, D. L.; WEBER, O.B.; CAZETTA, J.O. Comprimento de estacas e parte do ramo na formação de mudas de aceroleira. Revista Brasileira de Fruticultura, v.28, n.1, p.83-86, 2006.

LOLLI, A.P.O. Influência do ácido indolbutírico no enraizamento de estacas semilenhosas de Lippia alba (Mill.) N.E.Br. In: Jornada Paulista de Plantas Medicinais, 5., 2001, Botucatu-SP. Anais... Botucatu: UNESP. 2001. p.112-113.

LORENZI, H.; MATOS, F.J.A. Plantas medicinais no Brasil: nativas e exóticas. 2 ed. Nova Odessa: Instituto Plantarum, 2008. 544p.

MIRANDA, C.S.; CHALFUN, N.J.; HOFFMANN, A.; DUTRA, L. F.; COELHO, G.V.A. Enxertia recíproca e AIB como fatores indutores do enraizamento de estacas lenhosas dos porta-enxertos de pessegueiro 'Okinawa' e umezeiro. Ciência e Agrotecnologia, v. 28, n. 4, p. 778-784, 2004.

NICOLOSO, F.T.; CASSOL, L.F; FORTUNATO, R.P. Comprimento da estaca de ramo no enraizamento de ginseng brasileiro (Pfaffia glomerata). Ciência Rural, Santa Maria, v.31, n.1, p.57-60, 2001.

OLIVEIRA, G.L.; FIGUEIREDO, L.S.; MARTINS, E.R., COSTA, C.A. Enraizamento de estacas de Lippia sidoides Cham. utilizando diferentes tipos de estacas, substratos e concentrações de ácido indolbutírico. Revista Brasileira de Plantas Medicinais, Botucatu, v. 10, n.4, p. 12-17, 2008.

OLIVEIRA, L.M.; NEPOMUCENO, C.F.; FREITAS, N.P.; PEREIRA, D.M.S.; SILVA, G.C.; LUCCHESE, A.M. Propagação vegetativa de Hyptis leucocephala Mart. ex Benth. e Hyptis platanifolia Mart. ex Benth. (Lamiaceae) Revista Brasileira de Plantas Medicinais, v.13, n.1, p.73-78, 2011.

PASQUAL, M.; CHALFUN, N.N.J.; RAMOS, J.D.; VALE, M.R.; SILVA, C. R. R. Fruticultura comercial: propagação de plantas frutíferas. Lavras: UFLA: FAEPE, 2001. 137p.

PIMENTA, M.R.; FERNANDES, L.S.; PEREIRA, U.J.; GARCIA, L.S.; LEAL, S.R.; LEITÃO, S.G.; SALIMENA, F.R.; VICCINI, L.F.; PEIXOTO, P.H.P. Floração, germinação e estaquia em espécies de Lippia L. (Verbenaceae). Revista Brasileira de Botânica, v. 30, p. 211-220, 2007

QUIRANTES PINÉ, R; FUNES, L; MICOL, V; SEGURA CARRETERO, A; FERNÁNDEZ GUTIÉREZ, A. High performance liquid chromatography with diode array detection coupled to electrospray time- of- flight and ion-trap tandem mass spectrometry to identify phenolic compounds from a lemon verbena extract. Journal Chomatografy A, v. 1216, p. 5391-5397, 2009.

SAS INSTITUTE. SAS: user's guide statistics: version 8.0 edition. Cary, 1999.956 p.

STEFANINI, M.B.; MING, L.C.; UESUGI, G. F. 2004. Influence of IBA and boric acid on rooting of stem-cuttings of Aloysia triphylla (L'Hérit) Britton. Acta Horticulturae v. 629, p. 329-332,2004.

Rev. Bras. PI. Med., Campinas, v.16, n.1, p.25-31, 2014. 